\title{
ANALISIS BIAYA TRANSPORTASI DISTRIBUSI PUPUK MENGGUNAKAN SOFTWARE LINGO
}

\author{
Fitria Noor Aida ${ }^{1^{*}}$ dan Windi Rahmanda ${ }^{2}$ \\ ${ }^{1,2}$ Program Studi Teknik Industri, Universitas Widyatama, \\ J1. Cikutra No.204 Cibeunying Kidul, Kota Bandung, 40125 \\ *email: fitria.noor@widyatama.ac.id
}

\begin{abstract}
The distribution of fertilizers in Central Sulawesi Province has not been efficient due to the large transportation costs in March 2016, the distribution of fertilizers could not go directly to retailers because the distance between regencies was far enough so that fertilizer was sent to distributors before to retailers to minimize costs to be incurred. company. Transhipment problems are in the form of indirect distribution problems because the products sent must go through several stages before reaching the consumer. This study will compare the Vogel Approximation method in previous studies with the completion of linear programming with Lingo software tools. Transportation costs using the Vogel Approximation method in previous studies compared with transportation costs using the Lingo software tool have the same cost of IDR 508,289,000, but there are several different fertilizer distributions. Lingo software simplifies data processing so that the results obtained are more accurate than the Vogel Approximation method. Companies can use lingo software to minimize costs by working effectively and efficiently.
\end{abstract}

Keywords: Distribution, Transshipment, Software Lingo

\section{Pendahuluan}

Inefisiensi dan ketidakteraturan dalam sistem logistik masih menjadi kendala di dalam aktivitas logistik (Fatma \& Kartika, 2017). Kapasitas produk dan distribusi menjadi hal yang paling berpengaruh dalam pemeliharaan pasar. Perusahaan harus menyesuaikan kapasitas produksi dengan perkembangan pasar. Kapasitas produksi yang lebih kecil dibanding perkembangan pasar berpengaruh terhadap permintaan yang tidak terpenuhi. Kapasitas produksi yang lebih tinggi dibanding perkembangan pasar berpengaruh terhadap banyaknya persediaan yang menumpuk sehingga menimbulkan kerugian (Ikhyandini Garindia Atristyanti, 2015)

Distribusi merupakan sebuah aktivitas yang dianggap sangat penting didalam sebuah perusahaan. Pendistribusian tersebut digunakan untuk menyalurkan hasil produknya kepada konsumen. Namun, sering kali proses distribusi mengalami kendala karena permasalahan transportasi. Rute dalam pengiriman produk sangat berpengaruh dalam meminimalkan biaya transportasi, perusahaan dapat menentukan jalur terpendek yang ditempuh oleh setiap truk untuk menyalurkan produk kepada agen. Jarak menjadi faktor utama dalam menentukan rute truk, Semakin kecil total jarak yang ditempuh pada saat proses distribusi, maka semakin kecil biaya dan waktu yang digunakan(Ramadhani et al., 2018). Jarak dan kapasitas merupakan kendala utama bagi perusahaan untuk menghemat biaya yang dikeluarkan dalam distribusi produknya dimana terkadang menimbulkan kerugian bagi perusahaan (Rosta \& Tannady, 2012). Upaya untuk mengurangi biaya dan meningkatkan layanan kepada konsumen dalam pendistribusian produk dapat dikembangkan menjadi pendistribusian dengan model transhipment (Muhammad et al., 2013).

Model transhipment merupakan suatu masalah transportasi dimana sebagian atau seluruh barang yang diangkut dari sumber tidak langsung dikirim ke tempat tujuan tetapi melalui transit (Basriati et al., 2018). Menentukan jumlah produk yang akan 
dikirim dari suatu sumber ke tempat tujuan akhir melalui tempat transit dengan ketentuan kebutuhan pada tempat tujuan akhir bisa dipenuhi dengan biaya seminimal mungkin merupakan tujuan utama masalah transhipment (Basriati et al., 2018). Masalah transhipment merupakan perkembangan dari masalah transportasi yang membahas tentang meminimumkan biaya pendistribusian barang dari suatu tempat ke tempat lain secara tidak langsung, yakni harus mengalami dua atau lebih cara pengangkutan sebelum barang sampai ketempat (Batubara et al., 2018)

Model transportasi dan distribusi merupakan salah satu hal yang sangat penting dalam menjalankan aktivitas dan mempengaruhi keberhasilan sistem pendistribusian, distribusi yang baik akan menghasilkan penyaluran produk kepada konsumen menjadi lebih efektif. Meluasnya permintaan akan kebutuhan produk disuatu daerah menjadi masalah transportasi dan distribusi untuk pengembangan perusahaan (Yuli Ratnasari, Desi Yuniarti, 2019) Kasus transportasi timbul ketika suatu perusahaan mencoba menentukan cara pengiriman (distribusi) suatu jenis barang (item) dari beberapa sumber (lokasi penawaran) ke beberapa tujuan (lokasi permintaan) yang dapat menimimumkan biaya (Ardhyani, 2017)

Pada perkembangannya metode transportasi dapat diperluas dengan metode transhipment. Metode transhipment menjadi perluasan dari model transportasi dimana pada model transhipment semua distibutor berpotensi menjadi tempat persinggahan barang atau titik transshipment, pada metode transportasi pengiriman produk dilakukan secara langsung dari pabrik yang kelebihan produk kepada gudang yang membutuhkan produk dengan tujuan menyuplai produk yang ada di pabrik asal sedemikian rupa hingga terpenuhi semua kebutuhan pada tempat tujuan (Aisyah et al., 2018)

Pendistribusian pupuk di provinsi Sulawesi Tengah yang luas memberikan wewenang kepada perusahaan untuk mendistribusikan pupuk kepada distributor dan pengecer sebelum pupuk sampai kepada petani. Masalah yang ditemui biasanya berupa pendistribusian yang tidak efisien seperti terjadinya pembengkakan biaya transportasi yang disebabkan oleh pengalokasian pupuk yang tidak optimal. Perusahaan memerlukan metode yang bisa digunakan untuk pendistribusian yang efisien agar tujuan meminimalkan biaya transportasi dapat terpenuhi. Penelitian ini akan membandingkan biaya pendistribusian pupuk di wilayah sulawesi tengah menggunakan metode vogel approximation pada penelitian terdahulu dengan penyelesaian linear proggraming dengan tools software Lingo, untuk memberikan informasi metode terbaik yang harus diambil perusahaan agar biaya transportasi yang dikeluarkan dapat seminimal mungkin.

\section{Landasan Teori}

\section{a. Transportasi}

Fidel Miro megatakan bahwa transportasi adalah usaha pemindahan atau pergerakan dari suatu lokasi yang lainnya dengan menggunakan suatu alat tertentu (Iswanti \& Hasibuan, 2016)

Model transportasi adalah aplikasi dari model program linear yang merupakan suatu prosedur iteratif untuk pemecahan masalah minimasi biaya pengiriman atau distribusi dari pabrik atau sumber ke tempat tujuan (Trisnani, 2017).

Ciri-ciri khusus masalah transportasi adalah sebagai berikut (Syaripuddin, 2012) :

1. Terdapat sejumlah sumber dan sejumlah tujuan tertentu.

2. Kuantitas komoditas atau barang yang didistribusikan dari setiap sumber dan yang diminta oleh setiap tujuan besarnya tertentu .

3. Komoditas yang dikirim atau diangkut dari suatu sumber ke suatu tujaun besarnya sesuai dengan permintaan dan atau kapasitas sumber.

4. Ongkos Pengangkutan komoditas dari suatu sumber ke suatu sumber tujuan besarnya tertentu.

b. Transhipment

Transhipment adalah metode perkembangan dari masalah transportasi yang membahas tentang meminimumkan biaya pendistribusian barang dari suatu tempat ke tempat lain secara tidak langsun, yakni harus mengalami dua atau lebih cara pengangkutan sebelum barang sampai ke tempat tujuan (Batubara et al., 2018).

Cara penyelesaian dalam perubahan masalah transshipment ke masalah transportasi meliputi beberapa bagian, yaitu (Batubara et al., 2018) :

1) Menyeimbangkan tabel. Teiliti apakah jumlah persediaan barang (node bertanda +) sama 
dengan jumlah permintaan (node bertanda - ). Jika belum sama maka tabel harus diseimbangkan dengan menambahkan dummy.

2) Tentukan titik sumber, titik tujuan, dan titik perantara.

3) Tentukan jumlah persediaan dan permintaan tiap titik.

4) Tentukan biaya pengiriman.

c. Vogel Aproximation Method (VAM)

Vogel Aproximation Method merupakan cara yang lain yang dapat digunakan untuk menyelesaikan kasus transportasi dengan lebih mudah dan lebih cepat. Namun demikian, penyelesaian yang diperoleh kadang belum optimal, tetapi hanya mendekati optimal. Hasil penyelesaian masih bisa dioptimalkan dengan metode lain, seperti metode MODI (Trisnani, 2017).

Langkah-langkah metode Vogel Aproximation

Method sebagai berikut (Trisnani, 2017):

1) Tentukan perbedaan dua biaya terkecil pada setiap baris dan setiap kolom pada tabel.

2) Pilih nilai perbedaan terbesar, dimana baris atau kolom yang mempunyai nilai perbedaan terbesar merupakan baris atau kolom awal pengisian.

3) Kemudian pilih sel pada baris atau kolom yang terpilih mempunyai biaya terendah di mana sel ini akan dilakukan pengisian.

4) Berdasarkan baris dan kolom yang tersisa, ulangi langkah satu untuk baris atau kolom yang belum terisi, lalu lanjutkan ke point tiga dan empat.

\section{Metodelogi Penelitian}

Langkah yang dilakukan pada penelitian untuk mengumpulkan informasi, data serta hasil penelitian dapat dilihat pada metodologi penelitian. Metodologi penelitian didalam penelitian ini terdapat dalam beberapa tahap diantara dapat dilihat pada Gambar 1.

\section{Penentuan Masalah}

Penentuan masalah dapat terlihat aktifitas penditribusian pupuk yang kurang efektif di provinsi sulawesi tengah, setelah diketahui masalah kemudian dicari solusi atau metode yang belum pernah digunakan oleh perusahaan untuk memecahkan masalah yang terjadi di perusahaan.

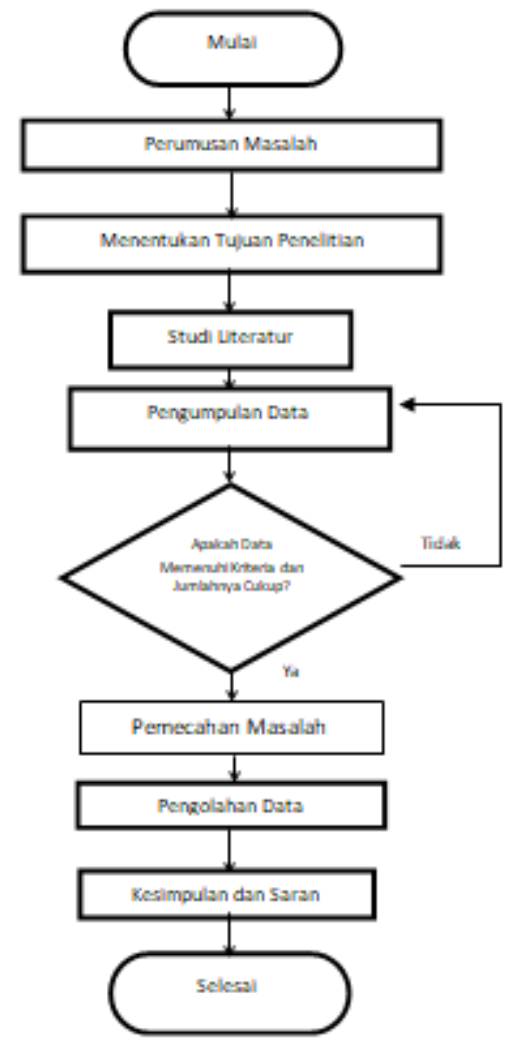

Gambar 1. Flowchart metode penelitian

\section{Studi Literatur}

Penelitian tentu saja harsu didasari oleh pengetahuan yang ilmiah, penyusunan yang sistematis harus dilakukan agar mempermudah langkah-langkah yangakan diambil pada saat penelitian. Langkah pertama melakukan studi litelatur terhadap buku-buku, jurnal ataupun penelitian mengenai riset operasi khususnya transportasi ataupun transhipment dan sofware yang digunakan yaitu software lingo,informasi yang didapat dari studi litelatur akan berguna untuk berlangsungnya penelitian.

\section{Pengumpulan Data}

Data yang digunakan didalam penelitian ini didapatkan dari jurnal yang berjudul Optimalisasi Pendistribusian Pupuk Di Wilayah Sulawesi Tengah Melalui Model Transshipment Dengan Menggunakan Metode Vogel Approximation(Safir et al., 2016), data yang digunakan diantaranya kapasitas sumber, kapasitas distributor, permintaan pengecer, biaya dari pabrik ke distributor, biaya dari distributor ke pengecer, biaya transportasi pendistribusian pupuk pada bulan maret 2016 dan 
biaya transportasi pendistribusian pupuk pada bulan maret 2016 setelah menggunakan metode Vogel Approximation.

\section{Pemecahan Masalah}

Pemecahan masalah dilakukan untuk menemukan solusi yang akan membantu perusahaan dalam meminimumkan biaya transportasi, sehingga biaya pendistribusian menjadi lebih efisien. Langkah untuk pemecahan masalah yaitu dengan membuat model matematika agar terbentuk formulasi yang akan mempermudah pemecahan masalah.

\section{Pengolahan Data}

Pengolahan data yang dilakukan dalam pendistribusian pupuk di Sulawesi Selatan dengan menentukan pengalokasian pupuk sesuai jalur yang dihubungkan dari sumber sampai kepada pengecer dengan bantuan metode transhipment dan software lingo. Langkah-langkah yang digunakan untuk melakukan penyelesaian metode transhipment dengan Software Lingo diantaranya:
a. Membuat tabel model transhipment.
b. Mengubah model transhipment kedalam model transportasi umum.
c. Memuat model kedalam software lingo.
d. Menentukan solusi optimal.

\section{Kesimpulan}

Penarikan kesimpulan diambil dari perbandingan hasil solusi optimal yang didapatkan dari penelitian dengan data asli dari hasil penelitian sebelumnya. Kesimpulan yang diambil merupakan solusi terbaik untuk digunakan perusahaan yang bersangkutan terkait dengan rencana pendistribusian pupuk untuk masa yang akan datang.

\section{Hasil dan Pembahasan}

\section{Pengumpulan Data}

Data yang dibutuhkan dalam penelitian ini diantaranya:

a. Kapasitas Pabrik

Pupuk yang akan didistribusikan berasal dari dua perusahaan yang telah mendapatkan wewenang pemerintah untuk mendistribusikan pupuk bersubsidi, perusahaan yang dimaksud diantaranya PT Petrokimia Gersik dan PT
Pupuk Kaltim, berikut merupakan kapasitas pupuk yang dimiliki perusahaan:

Tabel 1. Kapasitas Pabrik

\begin{tabular}{cc}
\hline Pabrik & $\begin{array}{c}\text { Kapasitas } \\
\text { (Ton) }\end{array}$ \\
\hline PT Petrokimia Gersik & 822 \\
PT Pupuk Kaltim & 455 \\
\hline Total & $\mathbf{1 2 7 7}$
\end{tabular}

Sumber : Safir, 2016

b. Permintaan Pengecer

Pupuk yang telah sampai kepada distributor kemudian didistribusikan lagi kepada pengecer, ada 11 pengecer pupuk bersubsidi yang terdapat di Sulawesi Tengah, untuk nama pengecer dan permintaan pupuk dari pengecer dapat dilihat pada tabel 2 berikut ini:

Tabel 2. Permintaan Pengecer

\begin{tabular}{lc}
\hline \multicolumn{1}{c}{ Pengecer } & Permintaan (Ton) \\
\hline Toko Melati & 20 \\
KOP Bina Tani Mandri & 30 \\
Kios Suryani & 20 \\
Kios Herman & 189 \\
Kios Eka & 698 \\
Toko Sinar Tani & 50 \\
Toko Sahabat Tani & 110 \\
Toko Cendana Tani & 58 \\
UD Putra Tani & 60 \\
Dua Putra Jaya & 10 \\
Toko Semoga Indah & $\mathbf{1 2 7 7}$ \\
\hline
\end{tabular}

Sumber :Safir, 2016

C. Biaya dari pabrik ke Distributor

Biaya transportasi yang dikeluarkan untuk pengiriman pupuk dari pabrik ke distributor terdapat pada tabel dibawah ini : 
Tabel 3. Biaya dari Pabrik ke Distributor

\begin{tabular}{lcc}
\hline \multirow{2}{*}{ Distributor } & \multicolumn{2}{c}{ Pabrik } \\
\cline { 2 - 3 } & PT Petrokimia Gersik (Rp) & PT Pupuk Kaltim (Rp) \\
\hline T. GCS & - & 500000 \\
PT. Petani & 254500 & 500000 \\
CV. Buana Prima & 254500 & 500000 \\
UD. Prima Tani & 254500 & 500000 \\
PT. PPI & 254500 & 500000
\end{tabular}

Sumber : Safir, 2016

d. Biaya dari Distributor ke Pengecer

Biaya transportasi yang dikeluarkan untuk pemiriman pupuk dari Distributor ke pengecer dapat dilihat pada tabel 3.4 berikut ini:

Tabel 4. Biaya dari Distributor ke Pengecer

\begin{tabular}{|c|c|c|c|c|c|}
\hline Pengencer & T. GCS (Rp) & $\begin{array}{l}\text { PT. Petani } \\
\text { (Rp) }\end{array}$ & $\begin{array}{l}\text { CV. Buana } \\
\text { Prima (Rp) }\end{array}$ & $\begin{array}{l}\text { UD. Prima } \\
\text { Tani (Rp) }\end{array}$ & $\begin{array}{l}\text { PT. PPI } \\
\text { (Rp) }\end{array}$ \\
\hline Toko Melati & 220000 & 0 & 100000 & 0 & 100000 \\
\hline $\begin{array}{l}\text { KOP Bina Tani } \\
\text { Mandri }\end{array}$ & 220000 & 0 & 100000 & 0 & 100000 \\
\hline Kios Suryani & 40000 & 90000 & 0 & 0 & 90000 \\
\hline Kios Herman & 40000 & 90000 & 0 & 0 & 90000 \\
\hline Kios Eka & 180000 & 0 & 50000 & 0 & 50000 \\
\hline Toko Sinar Tani & 180000 & 0 & 50000 & 0 & 50000 \\
\hline Toko Sahabat Tani & 200000 & 70000 & 0 & 70000 & 70000 \\
\hline Toko Cendana Tani & 200000 & 70000 & 0 & 70000 & 70000 \\
\hline UD Putra Tani & 0 & 0 & 70000 & 70000 & 0 \\
\hline Dua Putra Jaya & 0 & 0 & 70000 & 70000 & 0 \\
\hline Toko Semoga Indah & 0 & 70000 & 0 & 0 & 70000 \\
\hline
\end{tabular}

Sumber : Safir, 2016 
e. Total Biaya Transportasi

Total biaya yang dikeluarkan untuk penditribusian pupuk dari pabrik hingga pengecer dan perbandingan total biaya apabila pengiriman menggunakan metode Vogel Approximation dapat dilihat pada tabel 5 berikut ini:
Tabel 5. Total Biaya Transportasi'

\begin{tabular}{l|c}
\hline Biaya Maret $2016(\mathrm{Rp})$ & $\begin{array}{c}\text { Biaya menggunakan Vogel } \\
\text { Approximation }(\mathrm{Rp})\end{array}$ \\
\hline 518.239 .000 & 508.289 .000 \\
\hline
\end{tabular}

Sumber : (Safir, 2016)

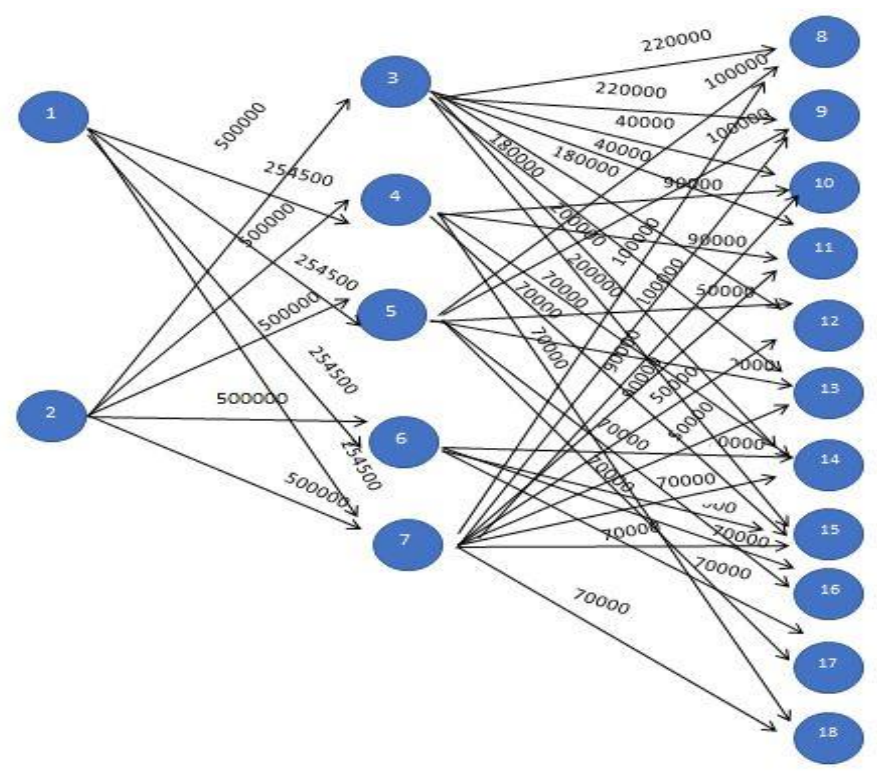

Gambar 2. Pendistribusian Pupuk

Sumber: Pengolahan Data

Gambar 2 menunjukan pendistribusian pupuk pada penelitian sebelumnya dengan menggunakan metode Vogel Approximation.

\section{Pemodelan Linear Programming}

1. Decision variable

$\mathrm{X}_{1,3}=$ banyaknya pupuk yang dikirim dari PT Petrokimia Gersik ke Distributor t GCS (Ton)

$\mathrm{X}_{2,3}$ = banyaknya pupuk yang dikirim dari PT Pupuk Kaltim ke Distributor t GCS (Ton)

$\mathrm{X}_{\mathrm{i}, \mathrm{j}}=$ banyaknya pupuk yang dikirim dari $\mathrm{i}$ ke $\mathrm{j}$ (Ton)

2. Parameter
$\mathrm{C}_{1,3}=$ biaya yang diluarkan untuk pengiriman dari PT Petrokimia Gersik ke Distributor $t$ GCS (Rupiah)

$\mathrm{C}_{2,3}=$ biaya yang diluarkan untuk pengiriman dari PT Pupuk Kaltim ke Distributor t GCS (Rupiah)

$C_{i, j}=$ biaya yang diluarkan untuk pengiriman dari i ke j (Rupiah)

3. Objective Function

Objective Function dari penelitian ini adalah untuk meminimalkan biaya transortasi dengan memperhitungkan jumlah pupuk yang akan diangkut dan biaya pengiriman.

MinimasiZ $=\left(C_{1,4} * X_{1,4}\right)+\left(C_{1,5} * X_{1,5}\right)+\left(C_{1,6} * X_{1,6}\right)+\left(C_{1,7} * X_{1,7}\right)+\left(C_{2,3} * X_{2,3}\right)+\left(C_{2,4} * X_{2,4}\right)+\left(C_{2,5} * X_{2,5}\right)+\left(C_{2,6} * X_{2,6}\right)+$ $\left(C_{2,7} * X_{2,7}\right)+\left(C_{3,8} * X_{3,8}\right)+\left(C_{5,8} * X_{5,8}\right)+\left(C_{7,8} * X_{7,8}\right)+\left(C_{3,9} * X_{3,9}\right)+\left(C_{5,9} * X_{5,9}\right)+\left(C_{7,9} * X_{7,9}\right)+\left(C_{3,10} * X_{3,10}\right)+$ $\left(C_{4,10} * X_{4,10}\right)+\left(C_{7,10} * X_{7,10}\right)+\left(C_{3,11} * X_{3,11}\right)+\left(C_{4,11} * X_{4,11}\right)+\left(C_{7,11} * X_{7,11}\right)+\left(C_{3,12} * X_{3,12}\right)+\left(C_{5,12} * X_{5,12}\right)+$ $\left(C_{7,12} * X_{7,12}\right)+\left(C_{3,13} * X_{3,13}\right)+\left(C_{5,13} * X_{5,13}\right)_{+}\left(C_{7,13} * X_{7,13}\right)+\left(C_{3,14} * X_{3,14}\right)+\left(C_{4,14} * X_{4,14}\right)+\left(C_{6,14} * X_{6,14}\right)+$ $\left.\left.\left(C_{7,14} * X_{7,14}\right)+\left(C_{3,15} * X_{3,15}\right)+C_{4,15} * X_{4,15}\right)+C_{6,15} * X_{6,15}\right)+\left(C_{7,15} * X_{7,15}\right)+\left(C_{5,16} * X_{5,16}\right)+\left(C_{6,16} * X_{6,16}\right)+$ $\left(C_{5,17} * X_{5,17}\right)+\left(C_{6,17} * X_{6,17}\right)+\left(C_{4,18} * X_{4,18}\right)+\left(C_{7,18} * X_{7,18}\right)$

Fungsi Pembatas : 
Sumber

$\mathrm{X}_{18}+\mathrm{X}_{19}+\mathrm{X}_{1,10}+\mathrm{X}_{1,11}+\mathrm{X}_{1,12}+\mathrm{X}_{1,13}+\mathrm{X}_{1,14}+\mathrm{X}_{1,15}+\mathrm{X}_{1,16}$

$+\mathrm{X}_{1,17}+\mathrm{X}_{1,18} \leq 822$

$\mathrm{X}_{28}+\mathrm{X}_{29}+\mathrm{X}_{2,10}+\mathrm{X}_{2,11}+\mathrm{X}_{2,12}+\mathrm{X}_{2,13}+\mathrm{X}_{2,14}+\mathrm{X}_{2,15}+\mathrm{X}_{2,16}$

$+X_{2,17}+X_{2,18} \leq 455$

Permintaan Pengecer

$\mathrm{X}_{3,8}+\mathrm{X}_{4,8}+\mathrm{X}_{5,8}+\mathrm{X}_{6,8}+\mathrm{X}_{7,8} \geq 20$

$\mathrm{X}_{3,9}+\mathrm{X}_{4,9}+\mathrm{X}_{5,9}+\mathrm{X}_{6,9}+\mathrm{X}_{7,9} \geq 30$

$X_{3,10}+X_{4,10}+X_{5,10}+X_{6,10}+X_{7,10} \geq 32$

$X_{3,11}+X_{4,11}+X_{5,11}+X_{6,11}+X_{7,11} \geq 20$

$X_{3,12}+X_{4,12}+X_{5,12}+X_{6,12}+X_{7,12} \geq 189$

$X_{3,13}+X_{4,13}+X_{5,13}+X_{6,13}+X_{7,13} \geq 69$
$X_{3,14}+X_{4,14}+X_{5,14}+X_{6,14}+X_{7,14} \geq 50$

$X_{3,15}+X_{4,15}+X_{5,15}+X_{6,15}+X_{7,15} \geq 110$

$X_{3,16}+X_{4,16}+X_{5,16}+X_{6,16}+X_{7,16} \geq 58$

$X_{3,17}+X_{4,17}+X_{5,17}+X_{6,17}+X_{7,17} \geq 60$

$X_{3,18}+X_{4,18}+X_{5,18}+X_{6,18}+X_{7,18} \geq 10$

$\mathrm{Xi}, \mathrm{j} \geq 0$

\section{Pengolahan Data}

Pengolahan data dilakukan dengan menggunakan software lingo, dengan formulasi model yang telah dibuat kemudian formulasi dimasukan kedalam sofware, untuk lebih jelasnya dapat dilihat pada gambar 3 berikut ini:

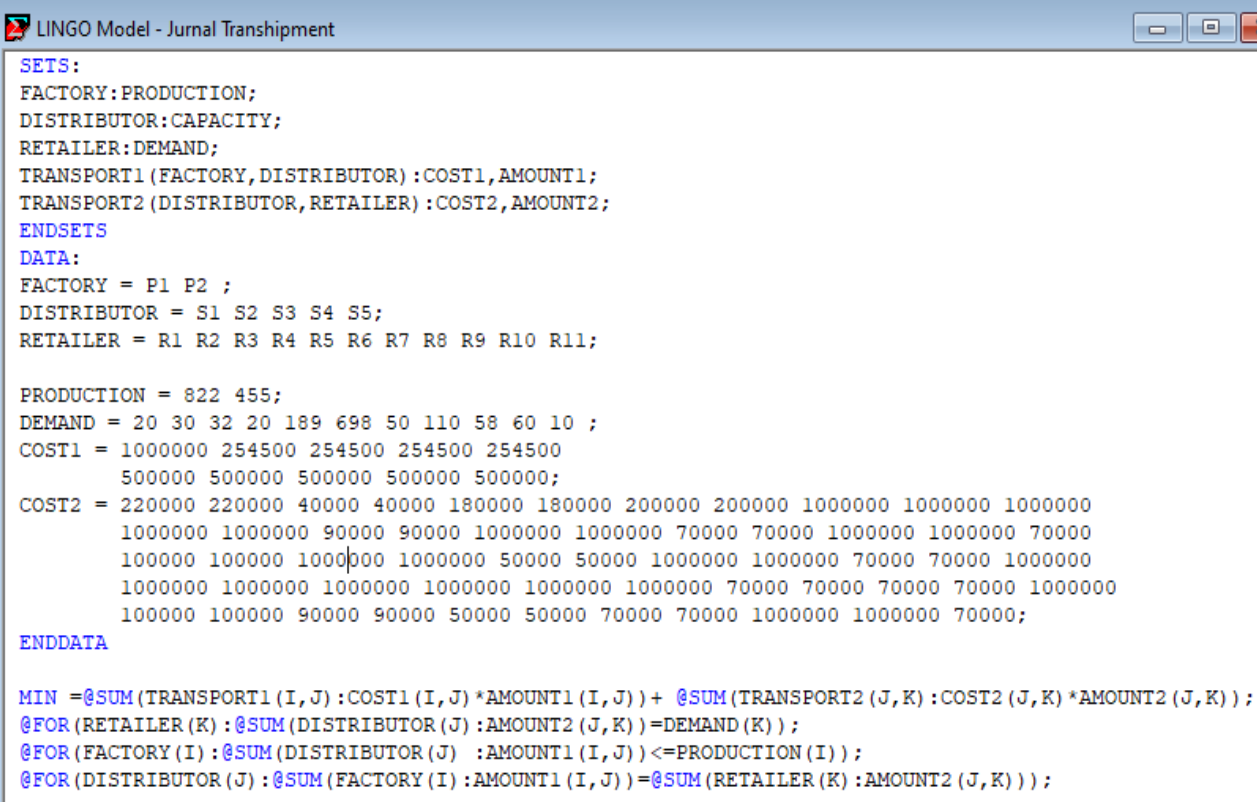

Gambar 3. Hasil Software Lingo Masalah Transshipment (Sumber : Pengolahan Data) 


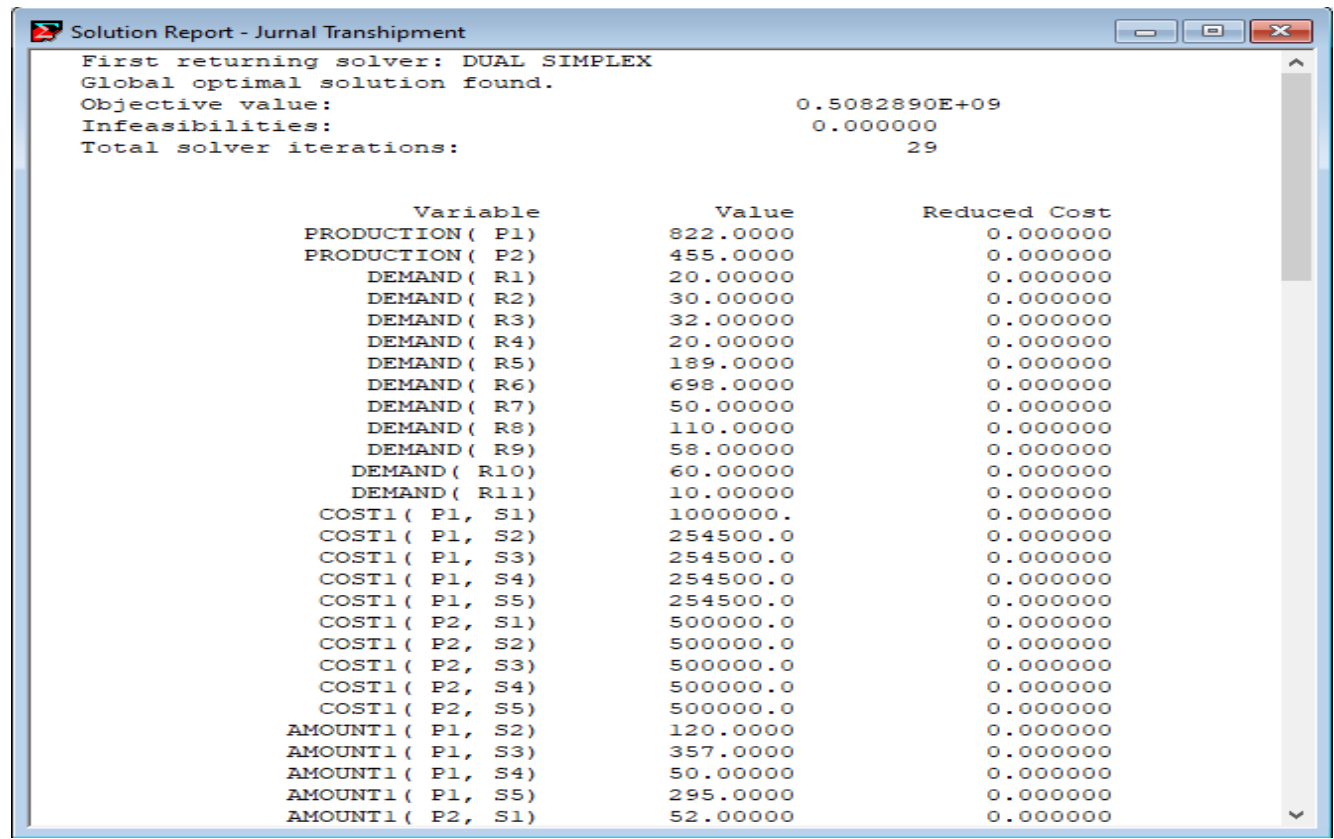

Gambar 4. Hasil Software Lingo Masalah Transshipment (Sumber : Pengolahan Data)

\begin{tabular}{|c|c|c|c|c|}
\hline \multicolumn{3}{|l|}{$\sum$ Solution Report - Jurnal Transhipment } & & $\square \square$ \\
\hline AMOUNTI ( & P2, s1) & 52.00000 & 0.000000 & 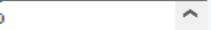 \\
\hline AMOUNTI i P & $\mathrm{P2}, \mathrm{S5})$ & 403.0000 & 0.000000 & \\
\hline $\cos 2(s$ & SI, R1) & 220000.0 & 0.000000 & \\
\hline $\cos 21 \mathrm{~s}$ & $S 1, R 2)$ & 220000.0 & 0.000000 & \\
\hline $\cos 2 i s$ & S1, R3) & 40000.00 & 0.000000 & \\
\hline $\operatorname{cost} 2 i \mathrm{~s}$ & S1, R4) & 40000.00 & 0.000000 & \\
\hline $\cos 2{ }_{2}(\mathrm{~s}$ & S1, R5) & 180000.0 & 0.000000 & \\
\hline $\cos 2 i s$ & S1, R6) & 180000.0 & 0.000000 & \\
\hline $\cos 21 s$ & S1, R7) & 200000.0 & 0.000000 & \\
\hline $\operatorname{cost} 2(\mathrm{~s}$ & si, & 200000.0 & 0.000000 & \\
\hline $\operatorname{cost} 2(s$ & S1, R9) & 1000000 . & 0.000000 & \\
\hline $\cos 22(\sin )$ & $1, R(0)$ & 1000000 . & 0.000000 & \\
\hline $\operatorname{cost} 2(s 1$, & 1, $R 11)$ & 1000000 . & 0.000000 & \\
\hline $\cos 2($ & S2, RI) & 1000000 . & 0.000000 & \\
\hline $\cos 22$ ( S: & $\mathrm{S} 2, \mathrm{R} 2)$ & 1000000. & 0.000000 & \\
\hline $\operatorname{cost} 2(\mathrm{~s})$ & S2, R3) & 90000.00 & 0.000000 & \\
\hline $\cos 21 \mathrm{~s}$ & S2, R4) & 90000.00 & 0.000000 & \\
\hline $\operatorname{cost} 2(\mathrm{~s})$ & S2, R5) & 1000000 . & 0.000000 & \\
\hline $\cos 22$ ( S & $S 2, \quad R 6$ ) & 1000000. & 0.000000 & \\
\hline $\operatorname{cost} 2$ ( $s$ & S2, R7) & 70000.00 & 0.000000 & \\
\hline $\cos 2 i s$ & $S 2, R 8)$ & 70000.00 & 0.000000 & \\
\hline $\operatorname{cost} 2 i s$ & S2, R9) & 1000000 . & 0.000000 & \\
\hline $\cos 12(\mathrm{~s} 2)$ & $2, R(0)$ & 1000000. & 0.000000 & \\
\hline $\operatorname{cost} 2(\mathrm{~s} 2$ & 2, R11) & 70000.00 & 0.000000 & \\
\hline $\operatorname{cost} 2(s$ & S3, R1) & 100000.0 & 0.000000 & \\
\hline $\operatorname{cost} 2(s$ & S3, R2) & 100000.0 & 0.000000 & \\
\hline $\cos 21 \mathrm{~s}$ & S3, R3) & 1000000 . & 0.000000 & \\
\hline $\operatorname{cost} 2$ is & S3, R4) & 1000000. & 0.000000 & \\
\hline $\operatorname{cost} 2 i s$ & S3, R5) & 50000.00 & 0.000000 & \\
\hline $\cos 2{ }_{2}(\mathrm{~s}$ & S3, R6) & 50000.00 & 0.000000 & \\
\hline $\cos 21 s$ & S3, R7) & 1000000 & 0.000000 & \\
\hline $\cos 12$ (s) & S3, R8) & 1000000. & 0.000000 & \\
\hline $\cos 2 i s$ & S3, R9) & 70000.00 & 0.000000 & \\
\hline $\cos 22(\mathrm{~s} 3$ & 3, R(O) & 70000.00 & 0.000000 & \\
\hline $\operatorname{cost} 2$ ( 53 & 3, RI1) & 1000000 . & 0.000000 & 6 \\
\hline
\end{tabular}

Gambar 5. Hasil Software Lingo Masalah Transshipment

(Sumber : Pengolahan Data) 


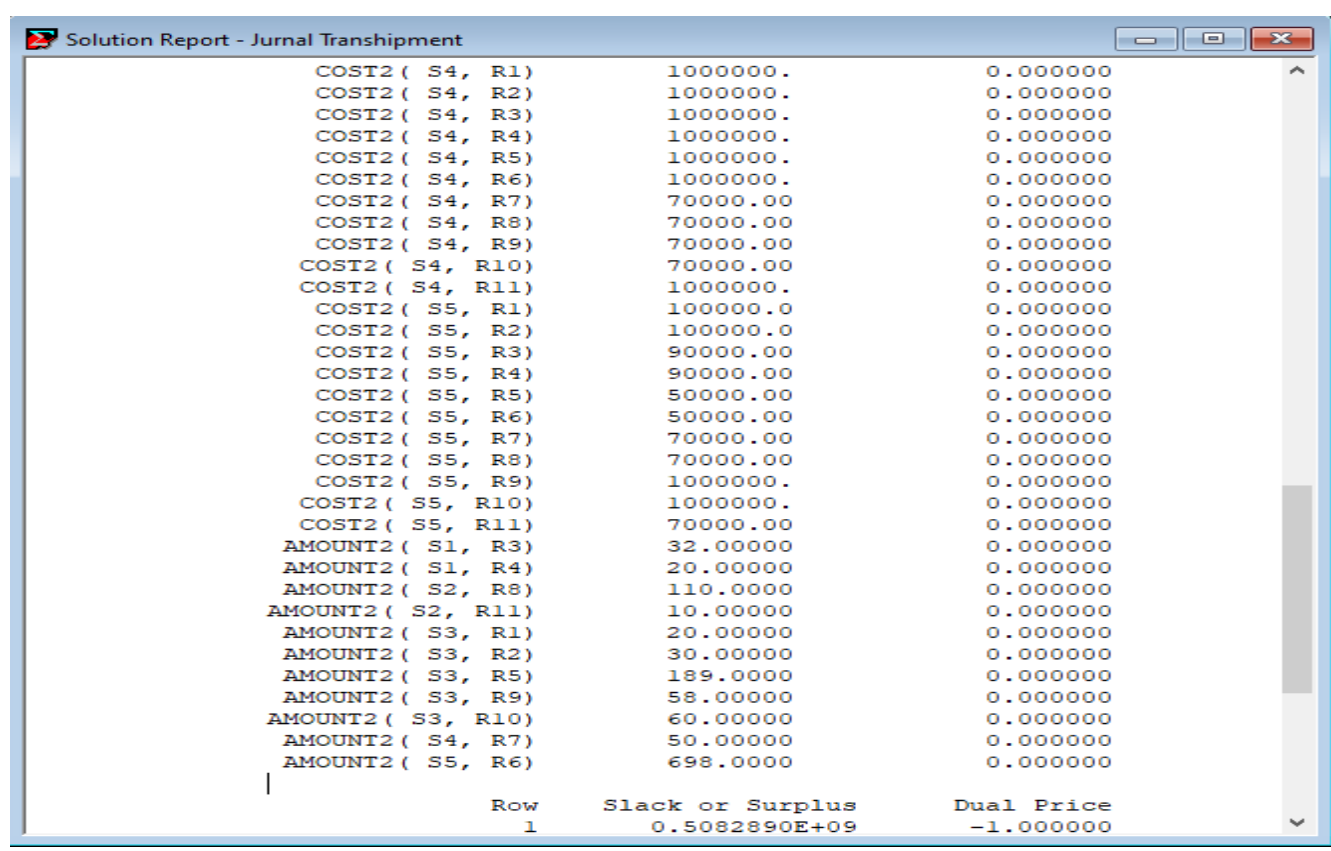

Gambar 6. Hasil Software Lingo Masalah Transshipment (Sumber : Pengolahan Data)

\begin{tabular}{|c|c|c|c|}
\hline$\sum$ Solution Report - Jurnal Transhipment & & & $\square \square$ \\
\hline $\operatorname{cosT2}(\mathrm{S} 5, \mathrm{R} 10)$ & 1000000 & 0.000000 & 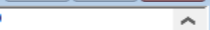 \\
\hline $\operatorname{cost2}(55, R 11)$ & 70000.00 & 0.000000 & \\
\hline AMOUNT2 ( S1, R3) & 32.00000 & 0.000000 & \\
\hline AMOUNT2 ( S1, R4) & 20.00000 & 0.000000 & \\
\hline AMOUNT2 ( S2, R8) & 110.0000 & 0.000000 & \\
\hline AMOUNT2 ( S2, RII) & 10.00000 & 0.000000 & \\
\hline AMOUNT2 ( S3, R1) & 20.00000 & 0.000000 & \\
\hline AMOUNT2 ( 53, R2) & 30.00000 & 0.000000 & \\
\hline AMOUNT2 ( S3, R5) & 189.0000 & 0.000000 & \\
\hline AMOUNT2 ( S3, R9) & 58.00000 & 0.000000 & \\
\hline AMOUNT2 ( $S 3$, RIO) & 60.00000 & 0.000000 & \\
\hline AMOUNT2 ( S4, R7) & 50.00000 & 0.000000 & \\
\hline AMOUNT2 ( $55, \mathrm{R} 6$ ) & 698.0000 & 0.000000 & \\
\hline Row & Slack or Surplus & Dual Price & \\
\hline 1 & $0.5082890 \mathrm{E}+09$ & -1.000000 & \\
\hline 2 & 0.000000 & -600000.0 & \\
\hline 3 & 0.000000 & -600000.0 & \\
\hline 4 & 0.000000 & -540000.0 & \\
\hline 5 & 0.000000 & -540000.0 & \\
\hline 6 & 0.000000 & -550000.0 & \\
\hline 7 & 0.000000 & -550000.0 & \\
\hline 8 & 0.000000 & -570000.0 & \\
\hline 9 & 0.000000 & -570000.0 & \\
\hline 10 & 0.000000 & -570000.0 & \\
\hline 11 & 0.000000 & -570000.0 & \\
\hline 12 & 0.000000 & -570000.0 & \\
\hline 13 & 0.000000 & 245500.0 & \\
\hline 14 & 0.000000 & 0.000000 & \\
\hline 15 & 0.000000 & -500000.0 & \\
\hline 16 & 0.000000 & -500000.0 & \\
\hline 17 & 0.000000 & -500000.0 & \\
\hline 18 & 0.000000 & -500000.0 & \\
\hline 19 & 0.000000 & -500000.0 & \\
\hline & & & $\checkmark$ \\
\hline
\end{tabular}

Gambar 7. Hasil Software Lingo Masalah Transshipment (Sumber : Pengolahan Data) 
Hasil yang didapatkan menggunakan software lingo, dengan formulasi model model yang telah dibuat, didapatkan distribusi pupuk sebagai berikut:

Pendistribusian pupuk dari Pabrik ke Distributor

PT Petrokimia Gersik- PT Petani $=120$

PT Petrokimia Gersik- CV Buana Prima $=357$

PT Petrokimia Gersik- UD Prima Tani= 50

PT Petrokimia Gersik- PT PPI = 295

PT Pupuk Kaltim - T GCS $=52$

PT Pupuk Kaltim - PT PPI $=403$

Pendistribusian pupuk dari Distributor ke Pengecer

T GCS- Kios Suryani $=32$

T GCS- Kios Herman $=20$

PT Petani-Toko Cendana Tani $=110$

PT Petani- Toko Semoga Indah $=10$

CV Buana Prima- Toko Melati $=20$

CV Buana Prima- KOP Bina Tani Mandiri $=30$

CV Buana Prima- Kios Eka $=189$

CV Buana Prima- UD Putra Tani $=58$

CV Buana Prima- Duo Putra Jaya $=60$

CV Prima Tani- Toko Sahabat Tani $=50$

PT PPI- Toko Sinar Tani $=698$

Total biaya yang harus dikeluarkan apabila alokasi pupuk seperti diatas yaitu:

$$
\begin{aligned}
& \text { Total Biaya = } \\
& \left(C_{1,4} X_{1,4}\right)+\left(C_{1,5} X_{1,5}\right)+\left(C_{1,6} X_{1,6}\right)+\left(C_{1,7}\right. \\
& \left.X_{1,7}\right)+\left(C_{2,3} \quad X_{2,3}\right)+\left(C_{2,7}\right. \\
& \left.X_{2,7}\right)+\left(C_{3,10} X_{3,10}\right)+\left(C_{3,11} X_{3,11}\right)+\left(C_{4,15}\right. \\
& \left.X_{4,15}\right)+\left(C_{4,18} X_{4,18}\right)+\left(C_{5,8} X_{5,8}\right)+\left(C_{5,9} X_{5}\right. \\
& , 9)+\left(C_{5,12} X_{5,12}\right)+\left(C_{5,16} X_{5,1}\right)+\left(C_{5,17} X_{5,1}\right. \\
& \text { 7) }+\left(C_{6,14} X_{6,14}\right)+\left(C_{7,6} X_{7,6}\right)
\end{aligned}
$$

Total Biaya $=(254.500 \times 10)+(254.500 \times 357)+$ $(254.500 \times 50)+(254.500 \times 295)+$ $(500.000 \times 52)+(500.000 \times 402)+$ $(40.000 \times 32)+(40.000 \times 20)+$ $(70.000 \times 110)+(70.000 \times 10)+$ $(100.000 \times 20)+(100.000 \times 30)+$ $(50.000 \times 189)+(70.000 \times 58)+$ $(70.000 \times 60+(70.000 \times 50+$ $(50.000 \times 698)=\operatorname{Rp} 508.289 .000,00$
Total biaya menggunakan Software Lingo sama besarnya dengan hasil penelitian sebelumnya menggunakan metode Vogel Approximation, tetapi terdapat beberapa pendistribusian pupuk yang berbeda. Pengolahan dengan menggunakan Software Lingo lebih mudah dilakukan, dengan jumlah iterasi sebanyak 29 iterasi akan ada kemungkinan banyaknya terjadi kesalahan yang disebabkan kurangnya ketelitian.

\section{Kesimpulan}

Biaya transportasi menggunakan metode Vogel Approximation dan Software Lingo menghasilkan biaya yang sama yaitu sebesar Rp 508.289.000,00, yang membedakan yaitu kelebihan perencanaan untuk penentuan biaya transportasi dengan menggunakan Software Lingo selain lebih mudah dalam pengolahan data, proses pengolahan data nya pun relatif lebih cepat dan lebih akurat dibanding dengan metode pengolahan Vogel Approximation, dapat dilihat jika iterasi yang dilakukan untuk mendapatkan biaya optimal sebanyak 29 kali iterasi, penggunaan metode Vogel Approximation akan rentan dalam terjadinya kesalahan, ketelitian harus sangat diperhatikan karena jika ada kesalahan pada iterasi awal maka semua pengolahan harus dimulai kembali dari awal. Berdasarkan penelitian dengan menggunakan Software Lingo perusahaan dapat menggunakan Software Lingo untuk melakukan pendistribusian yang lebih efisien.

\section{Daftar Referensi}

Aisyah, Purnamasari, I., \& Nasution, Y. N. (2018). Penerapan Metode Vogel's Approximation Method (VAM) dan Modified Distribution (MODI) Dalam Penyelesaian Transshipment Problem. Jurnal EKSPONENSIAL, 9(2), 187-196.

Ardhyani, I. W. (2017). Mengoptimalkan Biaya Distribusi Pakan Ternak Dengan Menggunakan Metode Transportasi (Studi Kasus Di Pt. X Krian). Teknika: Engineering and Sains Journal, 1(2), 95100.

https://doi.org/10.5281/zenodo.1116483

Basriati, S., Andriati, R., \& Safitri, E. (2018). Penyelesaian Model Transshipment dengan Metode Least Cost, North West Corner dan vogel's Approximation Method (Studi Kasus: PT. Subur Bangun Transport). Fakultas Sains Dan Teknologi, November, 
726-733.

Batubara, P., Rosmaini, E., \& Nababan, E. (2018). Kajian Masalah Transshipment Tidak Seimbang Menggunakan Metode Least Cost - Stepping Stone Dan Metode Least Cost Modi. Talenta Conference Series: Science and Technology (ST), 1(1), 049-058. https://doi.org/10.32734/st.v1i1.189

Fatma, E., \& Kartika, W. (2017). Penjadwalan dan Penentuan Rute Distribusi Komoditas ke Wilayah Timur Indonesia. Jurnal Optimasi Sistem Industri, 16(1), 40-49. https://doi.org/10.25077/josi.v16.n1.p4049.2017

Ikhyandini Garindia Atristyanti. (2015). Studi Penggunaan Packing Plant Pada Distribusi Semen Di Kalimantan Menggunakan Metode Transshipment. 20, 246-272.

Iswanti, N., \& Hasibuan, N. A. (2016). Aplikasi Transportasi Pengiriman Barang Menggunakan Metode Least Cost Dan Modified Distribution Pada CV . Nihta Cargo Express. 3(6), 106-110.

Muhammad, C. H., Abidin, Z., Matematika, J., \& Semarang, U. N. (2013). Optimalisasi Model Transshipment Di Pt. Primatexco Menggunakan Program Solver. Unnes Journal of Mathematics, 2(1), 65-69.

Ramadhani, F., Fathurrachman, F. A., Fitriawanti, R., Rongre, A. C., \& Wijayaningrum, V. N. (2018). Optimasi Pendistribusian Barang Farmasi Menggunakan Algoritma Genetika. Klik - Kumpulan Jurnal Ilmu Komputer, $5(2)$, https://doi.org/10.20527/klik.v5i2.151

Rosta, J., \& Tannady, H. (2012). Pendistribusian produk yang optimal dengan metode transportasi. Jurnal Teknik Dan Ilmu Komputer, 01, 347-352.

Safir, M., Musdalifah, S., \& Lusiyanti, D. (2016). Optimalisasi Pendistribusian Pupuk Di Wilayah Sulawesi Tengah Melalui Model Transshipment Dengan Menggunakan Metode Vogel Approximation. Jurnal Ilmiah Matematika Dan Terapan, 12(2), 211-221.

https://doi.org/10.22487/2540766x.2015.v12 .i2.7913

Syaripuddin. (2012). Program Studi Statistika FMIPA Universitas Mulawarman. Jurnal
EKSPONEN, 3, 1-8.

Trisnani. (2017). Analisa Perbandingan Metode Vam Dan Modi Dalam Pengiriman Barang Pada Pt . Mitra Maya Indonesia. Jurnal Pelita Informatika, 16, 311-317.

Yuli Ratnasari, Desi Yuniarti, dan I. P. (2019). Optimasi Pendistribusian Barang Dengan Menggunakan Vogel 's Approximation Method dan Stepping Stone Method ( Studi Kasus: Pendistribusian Tabung Gas LPG 3 Kg Pada PT . Tri Pribumi Sejati ) Optimization Of Goods Distribution Using Vogel , s Approximation. Jurnal EKSPONENSIAL, 10, 165-174.

\section{Informasi :}

Tata nama atau simbol yang di gunakan dalam jurnal adalah sebagai berikut :

$X_{l}=$ PT Petrokimia Gersik

$X_{2}=$ PT Pupuk Kalim

$X_{3}=$ Distributor $\mathrm{T}$ GCS

$X_{4}=$ Distributor PT Petani

$X_{5}=$ Distributor CV Buana Prima

$X_{6}=$ Distributor UD Prima Tani

$X_{7}=$ Distributor PPI

$X_{8}=$ Toko Melati

$X_{9}=$ KOP Bina Tani Mandiri

$X_{10}=$ Kios Suryani

$X_{11}=$ Kios Herman

$X_{12}=$ Kios Eka

$X_{13}=$ Toko Sinar Tani

$X_{14}=$ Toko Sahabat Tani

$X_{15}=$ Toko Cendana Tani

$X_{16}=$ UD Putra Tani

$X_{17}=$ Duo Putra Jaya

$X_{18}=$ Toko Semoga Indah 